\title{
Noticias y comentarios
}

\section{Publicaciones españolas sobre geografía de Chile (1981-2008)}

\section{Spanish publications on geography of Chile (1981-2008)}

Presentamos en este trabajo una relación de investigaciones sobre Chile publicadas en España, en revistas especializadas, actas de Congresos y algunas otras obras colectivas, con la intención de dar a conocer al lector interesado, tanto chileno como español, la existencia de esta producción científica, exponente del interés que el país andino ha generado en el nuestro durante los últimos treinta años.

La información proviene de las base de datos bibliográficas del Consejo Superior de Investigaciones Científicas (C.S.I.C.), concretamente, de la base de datos de Sumarios ISOC de Ciencias Sociales y Humanidades ${ }^{1}$ en sus áreas temáticas de América Latina y Geografía, Urbanismo y Arquitectura, gestionada por el Centro de Ciencias Humanas y Sociales (CCHS).

Dicha base de datos contiene la producción científica publicada en España desde los años 70 en los campos de actuación referidos -entre otros- recogiendo fundamentalmente artículos de revistas científicas y de forma selectiva actas de Congresos, series, compilaciones, informes y monografías.

La exhaustividad en el vaciado de las publicaciones, así como la rigurosidad en la catalogación e indización de las mismas y su constante actualización e incremento de las publicaciones tratadas, confieren a esta base de datos un

\footnotetext{
${ }^{1}$ http://bddoc.csic.es:8080/isoc.html;jsessionid=BA0B57C50A295E8BC24F342A92F098C3
} 
elevado nivel de pertinencia a la hora de la realización de las búsquedas documentales, convirtiéndola en un referente nacional e internacional en el campo de las fuentes de información.

Esta relación bibliográfica tiene igualmente interés en si misma como fuente de información sobre los temas chilenos de prioritaria atención entre los investigadores españoles o que por su importancia han superado los límites de la comunidad geográfica chilena para alcanzar cierta proyección internacional. Por eso, hemos incorporado también, cuestiones y temáticas de otras disciplinas, no sólo de Geografía, pero que guardan estrecha relación con la misma: urbanismo, medioambiente, historia, sociología, etc.

El trabajo se ha estructurado llevando a cabo, en primer lugar, un análisis de la información obtenida en las diferentes búsquedas documentales atendiendo a los siguientes criterios: cronología, autores, medios de edición y temáticas tratadas. Este último aspecto se refuerza con un índice de materias al que se le asignan las diferentes investigaciones.

En segundo lugar, se presenta una relación cronológica inversa de las publicaciones seleccionadas de acuerdo con la pertinencia marcada por los parámetros llevados a cabo en la búsqueda documental (toponímicos, de materias, etc.).

Y, por último, se relacionan las Revistas en las que aparecen dichos trabajos de investigación, con una pequeña reseña de las mismas que nos acerca a su temática y su vida editorial.

Así, lo primero que hay que destacar es el paulatino aumento de la producción bibliográfica en el periodo estudiado, que hemos iniciado en 1981, con un único ejemplo de investigación anterior a este período -concretamente de 1957-, recogido en esta relación bibliográfica por su interés en el ámbito científico. De esta forma, podremos valorar mejor el impacto que produjo la celebración del V Centenario del Descubrimiento, lo que lógicamente activó el mutuo interés entre España y toda Latinoamérica, y en particular con Chile que es el caso que aquí nos interesa. Y lo más importante es que esa activación se mantuvo tras la clausura de dicha celebración, como puede observarse en la fig. 1. alcanzándose el mayor número de publicaciones en el quinquenio siguiente, gracias, entre otras razones, a la publicación del anterior número monográfico de nuestra revista dedicada al país andino.

Los autores no son sólo españoles, una buena parte de ellos son chilenos o de otras nacionalidades del subcontinente, que bien sea por la celebración de coloquios y encuentros internacionales e iberoamericanos, bien por la mayor apertura de las revistas españolas, les ha resultado más fácil y accesible publicar en España. Nuestras revistas, en consecuencia, disponen con ello de una 
importante masa crítica del otro lado del Atlántico, gracias a la colaboración de estos autores que, por su lado, también se benefician de la posibilidad de una plataforma de edición en Europa, en su mismo idioma y cultura.

La mayoría de publicaciones lo ha sido en dos diferentes medios de edición: revistas periódicas y actas de congresos y reuniones científicas, aunque un buen número de colaboraciones fueron en sus orígenes comunicaciones a congresos publicados posteriormente en revistas periódicas. Es el caso de Scripta Nova, la única revista electrónica de todas las reseñadas, que publicó las comunicaciones presentadas a los Coloquios de Geocrítica. La amplia difusión que esta revista y esos coloquios tienen en el área latinoamericana ha determinado un elevado número de colaboraciones y que sea esa revista la que, precisamente y con mucho, la que más trabajos sobre Chile haya publicado en los últimos decenios.

Le sigue en número nuestra revista Estudios Geográficos, con once artículos, comenzando por el que, fuera del mencionado límite cronológico, publicara en 1957 el profesor Muñoz Pérez sobre La Perouse, en Chile. Luego vinieron algunas colaboraciones aisladas, tanto de autores españoles como chilenos y, sobre todo el volumen monográfico dedicado a este país, en 1999,

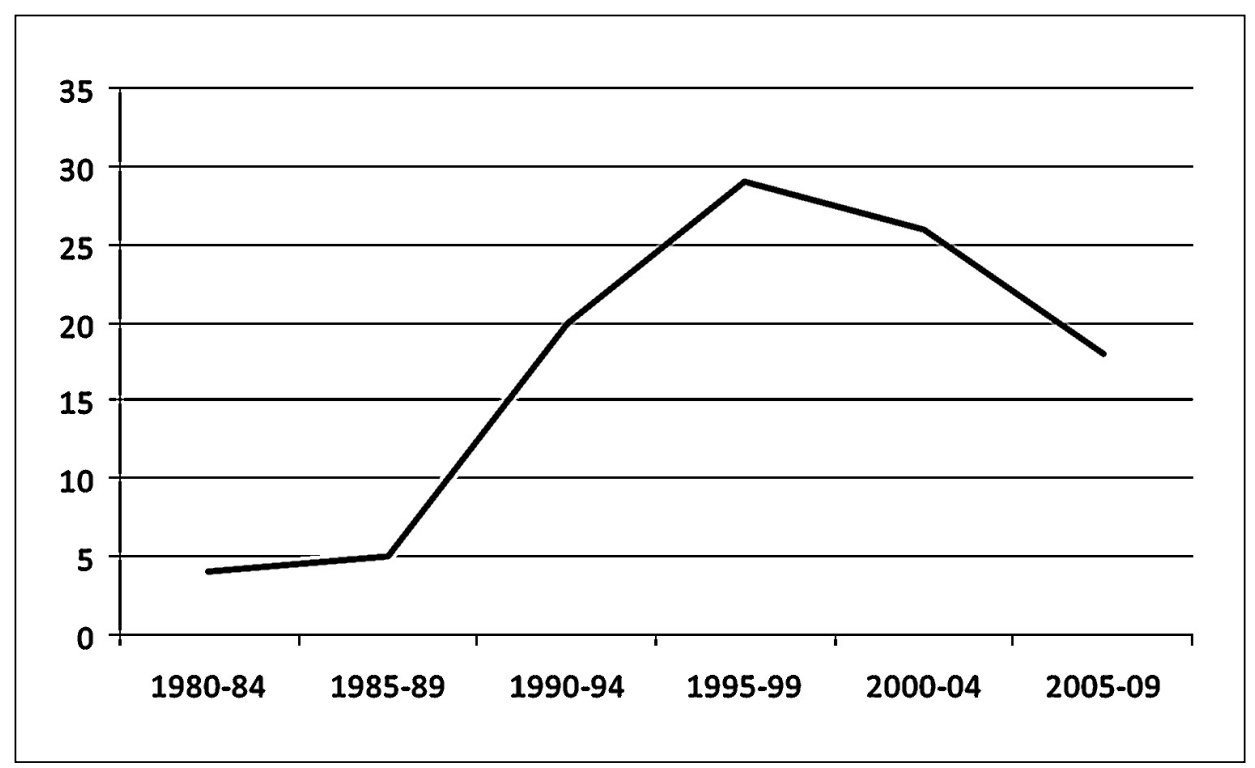

FIGURA 1. Evolución del número de publicaciones sobre Chile en revistas españolas (1980-2009) 
que hacía el número 60 de la colección. No incluimos, por razones obvias, los que constituyen este volumen, que esperamos suponga una actualización de la bibliografía reseñada.

La revista Pirineos, también del C.S.I.C. sirvió de soporte para publicar media docena de colaboraciones referentes a los Andes y algunos otros temas de geografía física relacionado con dicha cordillera. Le sigue en importancia Geographicalia, del Dpto. de Geografía de Zaragoza, con cuatro artículos, Cuadernos de Investigaciones Geográficas y Paralelo 37, ambas con tres. El resto, hasta un total de 22 revistas más, sólo han publicado, en estos últimos treinta años, uno o dos trabajos sobre el país andino.

Junto a las revistas periódicas, las reuniones científicas son el otro conjunto básico de las publicaciones reseñadas. Ya hemos citado el auténtico filón de aportaciones realizadas en los Coloquios de Geocrítica, el último de los cuales, celebrado en Porto Alegre en 2007, trató sobre Los problemas del mundo actual: respuestas y alternativas desde la geografía y las ciencias sociales, dando lugar a varias aportaciones sobre el tema chileno.

Igualmente, es preciso citar las reuniones de las asociaciones de americanistas en Salamanca (1996), Sevilla (2002) y Tordesillas (2005), así como las organizadas por el Centro de Estudios de América Latina de Catalunya (CEALC), destacando la celebrada en Tarragona en 2000 con el sugestivo tema: Amèrica Llatina: sumant visions davant el nou mil.leni.

El cambio de siglo y celebraciones del V Centenario son los dos temas que propiciaron otra serie de reuniones y congresos organizados por el grupo de la Asociación de Geógrafos Españoles sobre América Latina y otras instituciones similares, como los que tuvieron lugar en La Rábida, en 1992, bajo el significativo título de Latinoamérica. Territorios y Países en el umbral del siglo XXI, en Sevilla en 1999 y en Tordesillas (Valladolid) en 2001, con el nombre este último de América Latina en el cambio de siglo.

Las circunstancias socioeconómicas del continente, y su especial situación socioagraria, pueden explicar, por otro lado, la presencia de comunicaciones sobre Chile en los coloquios del grupo de Geografía Rural: VII (1994) Córdoba, X (2000) Lérida y XI (2002) Santander. Asimismo, también hemos recogido otras colaboraciones aisladas que, con carácter puntual, se presentaron a otros coloquios y reuniones habidas en España en esos años sobre emigración (Columbres-Ribadeva), Geografía Cuantitativa (Zaragoza) y Urbanismo (Valencia), todos ellos en 1992.

Como no podía ser de otra manera, la temática es muy variada, pero a pesar de ello podemos destacar algunas notas significativas, en relación tanto con la situación sociopolítica del país en estos últimos veinte años, como de la 
evolución de la ciencia geográfica. Predominan los temas urbanos, sociales y ambientales como corresponde a la actual coyuntura geopolítica de toda Latinoamérica.

Un buen número de los trabajos reseñados, muestran una clara preocupación por la temática ambiental, con especial atención a incendios y degradación de la vegetación en el Chile mediterráneo, junto a problemas de falta de agua en el norte árido o la degradación general provocada por la urbanización en la región de Santiago. Junto a ello, pueden citarse un buen número de estudios de Geografía Física más convencionales, con temas de vegetación, climatología, espacios y paisajes naturales, etcétera.

Pero el mayor interés de los investigadores se centra en temas urbanos con implicaciones sociales, políticas y territoriales. Interesan, sobre todo, los procesos de urbanización, el desarrollo de las principales áreas metropolitanas del país, como Santiago, Concepción, Puerto Montt, etc. con algún trabajo de interés sobre el sistema urbano chileno, su estructura y configuración. Otro buen número de artículos se refieren a problemas de vivienda, áreas residenciales, condominios, etc., aspectos que son tratados bien desde la perspectiva territorial o mejor social, dado la conflictividad que estas cuestiones presentan en el país estudiado. Asimismo, varios trabajos pueden integrarse en una perspectiva social más amplia, pero casi siempre manteniendo su reflejo sobre el territorio: grupos sociales, marginación, creación de espacio social y una referencia a la cuestión del género, tratado con una perspectiva histórica y retrospectiva.

Las cuestiones territoriales propiamente dichas están también bien representadas como consecuencia de tras variables geográficas de especial relevancia en el caso chileno: la morfología física característica del país, las transformaciones económicas experimentadas en los últimos años y los cambios políticos y administrativos derivados del fin de la dictadura, lo que ha determinado una serie de publicaciones sobre cuestiones de reordenación territorial, organización administrativa, de límites con países vecinos, etc. Asimismo, con ello podemos relacionar otras temáticas afines, también de especial incidencia territorial, como actividades productivas, turismo, planificación organización regional, etcétera.

Especial interés tienen las implicaciones sociodemográficas y económicas de esta particular coyuntura de la historia chilena, con atención a problemas de envejecimiento, éxodo rural, migraciones interiores y exteriores, particularmente la emigración española a Chile de épocas pasadas. Asimismo, hay que destacar algunos trabajos relativos a la evolución de la sociedad campesina tradicional, con especial atención a la modernización agraria y al turismo rural. 


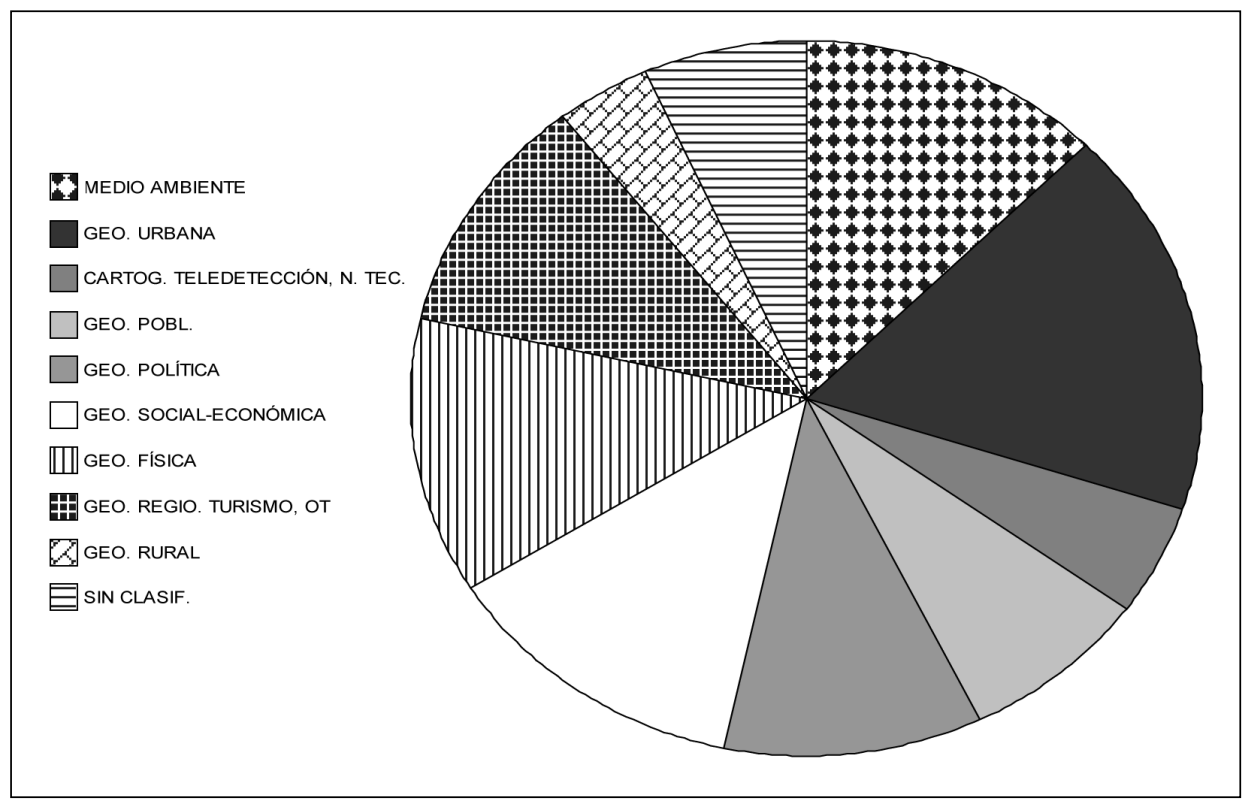

FIGURA 2. Distribución de publicaciones sobre Chile en revistas españolas (1980-2009), según temas

Por último, en esta amplia variedad temática se dan también algunos interesantes trabajos metodológicos referentes a la aplicación de sensores remotos para estudio y cartografía de vegetación y zonas verdes, áreas urbanas y cartografía convencional. Todo ello, constituye un importantes corpus bibliográfico sobre la geografía del país andino, claro exponente del interés que la geografía de Chile ha ido adquiriendo en nuestro país en los últimos años, y del que la publicación del presente volumen de Estudios Geográficos no pretende ser más que un simple eslabón.

\section{ÍNDICE DE MATERIAS}

- Cartografía, Teledetección, Nuevas Tecnologías: 5. 40. 43. 86. 87. 93.

- Geografía Económica: 26. 35. 53. 65. 72. 73. 82. 96.

- Geografía Física: 5. 17. 21. 37. 38. 44. 49. 52. 60. 66. 69. 78. 85. 90. 93. 95. 97. 100. 102.

- Geografía Histórica: 64. 71. 74. 103. 
— Geografía de la Población: 6. 32. 36. 54. 61. 84. 94.

- Geografía Política: 7. 24. 26. 42. 49. 58. 65. 91. 96.

- Geografía Regional, Turismo y Ordenación del territorio: 8, 9. 30.34. 35. 39. 41. 45. 47. 59. 68. 70. 82. 92. 96. 99.

— Geografía Rural: 18. 30. 31. 41. 75. 76.

- Geografía Social: 4, 10. 12. 13. 16. 19. 22. 23. 25. 26. 28. 29. 32. 42.46. 50. 64. 68. 79. 83.

- Geografía Urbana: 3, 4, 8, 9, 10. 11. 13. 14. 16. 19. 20. 23. 24. 25.27. 29. 32. 33. 35. 40. 48. 62. 76. 81. 83. 87. 88. 89. 91. 98.

— Medio Ambiente: 1, 2, 10, 11. 17. 18. 38. 41. 48. 51. 57. 60. 63. 67. 77. 86.

— Metodología e Historia de la Geografía: 15. 55. 56. 80. 101. 103.

RELACIÓN CRONOLÓGICA DE ARTÍCULOS

2008

1) Quintanilla Pérez, Víctor

"Perturbaciones a la vegetación nativa por grandes fuegos de 50 años atrás, en bosques Nordpatagónicos. Caso de estudio en Chile Meridional"

Anales de Geografía de la Universidad Complutense, 28(1): 85-104

2007

2) Madaleno, Isabel María; Gurovich, Alberto

"Usos conflictivos del agua en el norte de Chile"

Boletín de la Asociación de Geógrafos Españoles, (45): 353-372

3) Pérez Bustamente, Leonel; Salinas Varela, Edison

"Crecimiento urbano y globalización: transformaciones del Área Metropolitana de Concepción, Chile. 1992-2002"

Scripta Nova. Revista Electrónica de Geografía y Ciencias Sociales, (251): 35

4) Hidalgo, Rodrigo; Zunino, Hugo; Álvarez, Lily

"El emplazamiento periférico de la vivienda social en el área metropolitana de Santiago de Chile: consecuencias socio espaciales y sugerencias para modificar los criterios actuales de localización" en IX Coloquio Internacional de Geocrítica. Los problemas del mundo actual: respuestas y alternativas desde la Geografía y las Ciencias Sociales ( Porto Alegre, 2007)

Scripta Nova. Revista Electrónica de Geografía y Ciencias Sociales, (245/27): 17 
2006

5) Morales, L.; Sobrino, J.; Castellaro, G.; El-Kharraz, J.; Parra, J. C.

"Método de estimación del fitovolumen leñoso en la zona semiárida de Chile mediante una imagen SPOT y mediciones de campo"

Revista de Teledetección, (26): 31-39

2005

6) Antón Pérez, José Ignacio

"Transición demográfica, envejecimiento y reforma de la seguridad social en América Latina. El caso de Chile" en XI Encuentro de Latinoamericanistas Españoles (Tordesillas, 2005): 754-786

Título de la obra colectiva La comunidad Iberoamericana de Naciones

7) Fernández Carrión, Miguel Héctor

"Conflictos por los límites de fronteras entre Argentina y Chile" en X Congreso de la Asociación Española de Americanistas (Sevilla, 2002): 1535-1569

Título de la obra colectiva Estudios sobre América, siglos XVI-XX

8) Pérez Bustamente, Leonel; Andaur Fuentealba, Carolina

"Ciudad imaginada, ciudad planificada. Planificación urbana de Los Ángeles (Chile) en el siglo xx" en VII Coloquio Internacional de Geocrítica. Los agentes urbanos y las politicas sobre la ciudad (Santiago, 2005)

Scripta Nova. Revista Electrónica de Geografía y Ciencias Sociales, 9(194/88): 22 p.

9) Zunino, Hugo Marcelo

"Construyendo ciudad desde lo local en lo global: el caso del proyecto Ribera Norte, Concepción, Chile" en VII Coloquio Internacional de Geocrítica. Los agentes urbanos y las políticas sobre la ciudad (Santiago, 2005)

Scripta Nova. Revista Electrónica de Geografía y Ciencias Sociales, 9(194/86): $11 \mathrm{p}$.

\section{0) Olave Farias, Dídima}

"El sistema urbano de Chile central. Desafíos sociales y medio ambientales" en VII Coloquio Internacional de Geocrítica. Los agentes urbanos y las políticas sobre la ciudad (Santiago, 2005)

Scripta Nova. Revista Electrónica de Geografía y Ciencias Sociales, 9(194/69): $13 \mathrm{p}$. 
11) Romero, Hugo; Vasquez, Alexis

"La comodificación de los territorios urbanizables y la degradación ambiental en Santiago de Chile" en VII Coloquio Internacional de Geocrítica. Los agentes urbanos y las políticas sobre la ciudad (Santiago, 2005)

Scripta Nova. Revista Electrónica de Geografía y Ciencias Sociales, 9(194/68): 18 p.

\section{2) Fernández Labbé, Marcos}

"Las comunidades de la sobriedad: la instalación de zonas secas como método de control del beber inmoderado en Chile, 1910-1930" en VII Coloquio Internacional de Geocrítica. Los agentes urbanos y las políticas sobre la ciudad (Santiago, 2005)

Scripta Nova. Revista Electrónica de Geografía y Ciencias Sociales, 9(194/59): $11 \mathrm{p}$.

\section{3) Paulsen, Abraham}

"Los espacios de redención en la ciudad contemporánea. Aproximaciones al avivamiento pentecostal de 1909 en Valparaíso, Chile" en VII Coloquio Internacional de Geocrítica. Los agentes urbanos y las políticas sobre la ciudad (Santiago, 2005)

Scripta Nova. Revista Electrónica de Geografía y Ciencias Sociales, 9(194/100): 23 p.

\section{4) Ortiz Veliz, Jorge; Escolano Utrilla, Severino}

"Los Mega-diseños residenciales vallados en las periferias de las metrópolis latinoamericanas y el advenimiento de un nuevo concepto de ciudad. Alcances en base al caso de Santiago de Chile" en VII Coloquio Internacional de Geocrítica. Los agentes urbanos y las politicas sobre la ciudad (Santiago, 2005)

Scripta Nova. Revista Electrónica de Geografía y Ciencias Sociales, 9(194/03): $14 \mathrm{p}$.

\section{5) Troncoso Meléndez, Andrés}

"Un espacio, tres paisajes, tres sentidos: la configuración rupestre en Chile central" en Reflexiones sobre arte rupestre, paisaje, forma y contenido, 33: 69-81

16) Hidalgo D., Rodrigo; Borsdorf M., Axel

"La exclusión residencial y el desarrollo de la ciudad moderna en América Latina: de la polarización a la fragmentación. El caso de Santiago de Chile" Geographicalia, (48): 5-29 
17) Quintanilla Pérez, Víctor

"Degradación del bosque Nordpatagónico en la Cuenca Superior del río Palena, Chile Meridional (43)"

Geographicalia, (47): 47-68

18) Montalba Navarro, René; Carrasco Heríquez, Noelia

"¿Desarrollo sostenible o eco-etnicidio?: el proceso de expansión forestal en territorio mapuche-nalche de Chile"

Ager. Revista de Estudios sobre Despoblación y Desarrollo Rural, (4): 101-133

2004

19) Escolano Utrilla, Serverino; Ortíz Véliz, Jorge

"La complejidad de los procesos de reestructuración socio espacial de las ciudades intermedias: persistencia y cambio en la ciudad de Puerto Montt (Chile)"

Anales de Geografía de la Universidad Complutense, 24: 79-106

20) Escolano Utrilla, Serverino; Ortíz Véliz, Jorge

"Cambios de la configuración urbana y «sintaxis del espacio» en ciudades intermedias: el caso de La Serana (Chile)"

Estudios Geográficos, 65(255): 297-320

21) Quintanilla Pérez, Víctor

"Antecedentes geobotánicos de una cuenca andina de Chile central"

Pirineos, (158-159): 43-59

2003

22) Margarit Segura, Daisy Verónica

"El sentido del bienestar en una política social de vivienda: El caso de la fase piloto del Chile Barrio" en V Coloquio Int. Geocrítica: La vivienda y la construcción del espacio social de la ciudad (Barcelona, 2003)

Scripta Nova. Revista Electrónica de Geografía y Ciencias Sociales, 7 (146/89): $10 \mathrm{p}$.

\section{3) Pérez Bustamente, Leonel}

"La vivienda como estrategia de revitalización urbana. Rehabilitación de pabellones mineros en Lota, Chile" en V Coloquio Int. Geocrítica: La vivienda y la construcción del espacio social de la ciudad (Barcelona, 2003)

Scripta Nova. Revista Electrónica de Geografía y Ciencias Sociales, 7 (146/57): 9 p. 


\section{4) Orellana, Arturo}

"Las dos caras del éxito de la política de vivienda en Chile: ¿Una cuestión de gobernabilidad metropolitana?" en V Coloquio Int. Geocrítica: La vivienda y la construcción del espacio social de la ciudad (Barcelona, 2003)

Scripta Nova. Revista Electrónica de Geografía y Ciencias Sociales, 7 (146/47): $11 \mathrm{p}$.

25) Falconi da Hora Bernardelli, Maria Lucia; Donizete Locatel, Celso; Ramalho Barbudo, Reolarde

"Reestructuración socio-espacial y segregación de viviendas: Los casos de Santiago de Chile, Mendoza y Buenos Aires" en V Coloquio Int. Geocrítica: La vivienda y la construcción del espacio social de la ciudad (Barcelona, 2003)

Scripta Nova. Revista Electrónica de Geografía y Ciencias Sociales, 7 (146/134): 13 p.

26) Fischer, Karin; Jäger, Johannes; Parnreiter, Christof

"Transformación económica, políticas y producción de la segregación social en Chile y México" en V Coloquio Int. Geocrítica: La vivienda y la construcción del espacio social de la ciudad (Barcelona, 2003)

Scripta Nova. Revista Electrónica de Geografía y Ciencias Sociales, 7 (146/127): $11 \mathrm{p}$.

27) Hidalgo Dattwyler, Rodrigo; Álvarez Correa, Lily; Salazar Barrows, Alejandro

"Los condominios y urbanizaciones cerradas como nuevo modelo de construcción del espacio residencial en Santiago de Chile (1992-2000)" en V Coloquio Int. Geocrítica: La vivienda y la construcción del espacio social de la ciudad (Barcelona, 2003)

Scripta Nova. Revista Electrónica de Geografía y Ciencias Sociales, 7 (146/123): $24 \mathrm{p}$.

\section{8) Hidalgo Dattwyler, Rodrigo; Cáceres Quiero, Gonzalo}

"Beneficencia católica y barrios obreros en Santiago de Chile en la transición del siglo XIX y Xx. Conjuntos habitacionales y actores involucrados" en $V$ Coloquio Int. Geocrítica: La vivienda y la construcción del espacio social de la ciudad (Barcelona, 2003)

Scripta Nova. Revista Electrónica de Geografía y Ciencias Sociales, 7 (146/100): $10 \mathrm{p}$. 


\section{9) Hidalgo Dattwyler, Rodrigo}

"Conflicto de alquileres y política de vivienda social en la década de 1920. El caso de Chile"

Estudios Geográficos, 64 (252): 387-406

2002

30) Castro Romero, Marisol

"Características del proceso de diferenciación campesina en el distrito de la Laguna de Aculeo (Chile): el turismo rural una nueva alternativa" en XI Coloquio de Geografía Rural (Santander, 2002), 303-314

Título de la obra colectiva Los espacios rurales entre el hoy y el mañana

31) Castro Romero, Marisol; Lardiés Bosque, Raúl

"Movilidad espacial y trabajo agrícola de la población residente en el distrito de la Laguna de Aculeo, Chile" en IV Coloquio Int. Neocrítica (Barcelona, 2002)

Scripta Nova. Revista Electrónica de Geografía y Ciencias Sociales, 6 (119/40): 1-12

32) Ortiz V., Jorge; Aravena A., Evelyn

"Migraciones intraurbanas y nuevas periferias en Santiago de Chile: Efectos en la sociogeografía de la ciudad"

Geofocus. Revista internacional de Ciencia y Tecnología de la información Geográfica, (2): 49-60

2001

\section{3) Hidalgo, Rodrigo}

"Políticas de vivienda y planeamiento urbano en Chile en la segunda mitad del siglo xx" en IV Congreso de CEALC (Tarragona, 2000): 138-141

Título de la obra colectiva Amèrica Llatina: sumant visions davant el nou mil.leni - América Latina: sumando visiones ante el nuevo milenio

34) Petagna del Río, Ana María

"El Corredor Bioceánico Sur Argentina-Chile explicado como espacio geográfico" en América Latina en el cambio de siglo. VI Congreso de Geografía de América Latina (Valladolid-Tordesillas, 2001): 13 p.

35) Romero, Hugo; Azócar, Gerardo

"Efectos regionales y urbanos de la reestructuración productiva en Chile" en América Latina en el cambio de siglo. VI Congreso de Geografía de América Latina (Valladolid-Tordesillas, 2001): 11 p. 


\section{6) Castro Romero, Marisol}

"El proceso migratorio de la población Mapuche en Chile: su adaptación e integración a la vida urbana" en III Coloquio Int. Neocrítica (Barcelona, 2001)

Scripta Nova. Revista Electrónica de Geografía y Ciencias Sociales, 5 (94/19): 1-17 p.

37) Capelli de Steffens, Alicia; Cintia Píccolo, María; Hernández González, Jorge; Navarrette, Gustavo

"La isla de calor estival en Temuco, Chile"

Papeles de Geografía, (33): 49-60

\section{8) Quintanilla Pérez, Víctor}

"Alteraciones del fuego sobre la biodiversidad de bosques templados. El caso del bosque costero pluvial de Chile"

Cuadernos Geográficos de la Universidad de Granada, (31): 7-21

39) Navarro Harris, Rayen Ximena

"Formas de ocupación y uso del espacio, en un sector costero del sur de Chile. La comprensión de un territorio"

Arqueología Espacial. Revista del Seminario de Arqueología y Etnología Turolense, (23): 227-247

\section{0) Herrera, V.}

"Estudio del crecimiento urbano de la ciudad de Valdivia (Chile) a través del uso integrado de imágenes de satélite, SIG y equipos G.P.S."

Revista de Teledetección, (15): 69-78

\section{0}

\section{1) Negrete Sepúlveda, Jorge}

"Instrumentos de planificación y ordenamiento del territorio para la sustentabilidad y sostenibilidad del desarrollo rural en Chile" en X Coloquio de Geografía Rural de España. Los espacios rurales en el cambio de siglo: incertidumbres ante los procesos de globalización y desarrollo (Lleida, 2000): 796-804

\section{2) Larraín Berguño, María José}

"De la innovación política a la innovación social: el Club de la Unión de Santiago de Chile" en II Coloquio Int. Geocrítica. Innovación, Desarrollo y Medio Local. Dimensiones Sociales y Espaciales de la Innovación. 2000

Scripta Nova. Revista Electrónica de Geografía y Ciencias Sociales, 4 (69/28): $1-13$ 
43) Álvarez Correa, Lily

"Cartografía y Geodesia: las innovaciones de la Oficina de Mensura de Tierras de Chile a principios del siglo xx (1907-1914)" en II Coloquio Int. Geocrítica. Innovación, Desarrollo y Medio Local. Dimensiones Sociales y Espaciales de la Innovación. 2000

Scripta Nova. Revista Electrónica de Geografía y Ciencias Sociales, 4 (69/12): $1-12$

44) Schröder, H.; Makki, M.

"Morfología periglacial del Volcán Llullaillaco (Chile/Argentina)"

Pirineos, (155): 3-36

45) Ferrer Jiménez, Daniel

"El Turismo en los Espacios Naturales Protegidos de Chile" en V Congreso del Grupo de América Latina (Sevilla, 1999): 425-436

Título de la obra colectiva Territorio y cooperación

46) Hidalgo Dattwyler, Rodrigo; Álvarez Correa, Lily

"La cooperación habitacional entre Chile y España: El caso de la Comunidad de Andalucía. La visión de los residentes" en V Congreso del Grupo de América Latina (Sevilla, 1999): 185-196

Título de la obra colectiva Territorio y cooperación

47) Álvarez Correa, Lily

"El catastro de bienes inmuebles como un instrumento de planificación territorial. La unidad vecinal 25. Comuna de la Florida, Santiago de Chile" en I Coloquio Int. de Geocrítica

Scripta Nova. Revista Electrónica de Geografía y Ciencias Sociales, 3 (45/2): 1-7

48) Brignardello Torralba, Luigi; Pérez Albert, Yolanda

"Desarrollo sostenible y ciudad. La comunidad ecológica de Peñalolen Alto (Peñalolen, Santiago de Chile)" en I Coloquio Int. de Geocrítica

Scripta Nova. Revista Electrónica de Geografía y Ciencias Sociales, 3 (45/19): $1-5$

49) Casals Costa, Vicente

"La política forestal en Chile. Una perspectiva histórica" en I Coloquio Int. de Geocrítica

Scripta Nova. Revista Electrónica de Geografía y Ciencias Sociales, 3 (45/16): $1-7$

Estudios Geográficos, Vol. LXX, 266, pp. 295-321, enero-junio 2009

ISSN: 0014-1496, eISSN: 1988-8546, doi: 10.3989/estgeogr.2158 


\section{0) Hidalgo Dattwyler, Rodrigo}

"La vivienda social en Santiago de Chile: la acción del Estado en un siglo de planes y programas" en I Coloquio Int. de Geocrítica

Scripta Nova. Revista Electrónica de Geografía y Ciencias Sociales, 3 (45/1): $1-7$

51) Petit-Breuilh Sepúlveda, María Eugenia

"Los desastres naturales en América: El aporte de la geografía histórica en el caso de Chile"

Rábida, (18): 25-34

52) Andrade J., Belisario

"El marco natural de Chile: su diversidad de paisajes"

Estudios Geográficos, 60 (234): 7-24

53) Sánchez Muñoz, Alfredo

"Los recursos naturales, las estrategias de crecimiento y el desarrollo económico de Chile"

Estudios Geográficos, 60 (234): 61-100

54) Gangas Geisse, Mónica

"El estado actual de la población en Chile"

Estudios Geográficos, 60 (234): 45-60

55) Rioseco Hormazabal, Reinaldo

"La investigación en el Instituto de Geografía de la Pontificia Universidad Católica de Chile"

Estudios Geográficos, 60 (234): 160-171

56) Georgudis Maya, Basilio

"Revista de Geografía «Norte Grande» Instituto de Geografía de la Pontificia Universidad Católica de Chile"

Estudios Geográficos, 60 (234): 157-159

57) Castro, Consuelo; Brignardello, Luigi

"El estado del Medio Ambiente en Chile"

Estudios Geográficos, 60 (234): 139-155

58) González Leiva, José Ignacio

"Geografía electoral de Chile: comportamiento del electorado chileno entre 1932 y 1992"

Estudios Geográficos, 60 (234): 121-138 
59) Arenas Vásquez, Federico

"Organización territorial y desarrollo regional en Chile"

Estudios Geográficos, 60 (234): 101-119

1998

60) Quintanilla Pérez, Victor; Castro, Roberto

"Seguimiento de las cubiertas vegetales post-incendios forestales en la zona mediterránea costera de Chile"

Serie Geográfica, 1997-1998, (7): 147-154

1997

61) Harris Bucher, Gilberto

"La inmigración extranjera en Chile a revisión: también proletarios, aventureros, desertores y deudores"

Anuario de Estudios Americanos, 54 (2): 543-566

\section{2) Vidal, Rodrigo}

"La idea de territorio en el ordenamiento urbano de santiago de Chile" en I Congreso Europeo de Latinoamericanistas (Salamanca, 1996) (Taller 14): 283-351

Título de la obra colectiva América latina. Realidades y perspectivas

63) Quintanilla Pérez, Víctor

"Evaluación de riesgos de incendios en los cordones montañosos costeros de Chile central"

Geographicalia, (35): 187-204

64) Varela, Brisa

"Notas sobre dos relatos del terremoto de 1822 en Chile: una lectura de género"

Documents d'Anàlisi Geogràfica, (30): 177-187

65) Toledo, Ximena; Romero, Hugo

"El nuevo mapa territorial de Chile: efectos espaciales de la aplicación del modelo neo-liberal en la economía nacional" en XVI Congreso Nacional de Geografía (Valdivia, 1995)

Rábida, (14-15): 109-116 
1996

66) Marzol, María V.; Cereceda, P.; Schemenauer, R.; Castro, C.

"Caracterización de la pluviosidad de Bahía Cumberland (Isla de Robinson Crusoe, Chile)"

Cuadernos de Investigación Geográfica, 1996-1997, 22-23: 97-114

67) Quintanilla Pérez, Víctor

"Alteraciones por el fuego en la cordillera de la costa de Chile Mediterráneo. Antecedentes en un Parque Nacional"

Pirineos, 46 (147-148): 97-113

68) García de Paredes Pérez, E.A.

"El problema de la vivienda en Chile y su utilización política en el proceso de regionalización: el ejemplo de Puerto Montt"

Revista Norba-Arte, 16: 351-365

69) Martínez de Pisón, Eduardo

"Las directrices morfológicas del sector andino entre el Lago O'Higgins y el Monte Fitz-Roy (Chile-Argentina)"

Ería, (41): 189-205

70) Cardone, Miriam; Martínez, María Nélida; Fernández, Sonia

"El ferrocarril trasandino y la integración con Chile" en Congreso Nacional de Ciencia Política. Globalización, entre el conflicto y la integración (Mendoza, 1995)

Geographicalia, (33): 73-88

1995

71) Relaciones Geográficas del Reino de Chile, 1995, 301 p.

72) Mattos, Carlos A. de

"Reestructuración, globalización, nuevo poder económico y territorio en el Chile de los noventa"

Revista de Estudios Regionales, (43): 69-100

73) Daher, Antonio

"Territorios del capital bancario y provisional en Chile"

Documents d'Anàlisi Geogràfica, (27): 37-55

1994

74) Relaciones económicas del Reino de Chile (1780), 1994, 268 p. 
75) Domic K., Lenka; Fuentes A., Adela; Bravo T., Jorge

"Cambios en el sector agrario de Chacabuco. Norte de Santiago de Chile" en VII Coloquio de Geografía Rural (Córdoba, 1994), 7: 591-597

76) Fuentes A., Adela; Acosta A., Patricia

"La modernización agrícola en la región metropolitana de Santiago de Chile y su impacto en las condiciones de vida del trabajador rural en la década de los ochenta" en VII Coloquio de Geografía Rural (Córdoba, 1994), 7: 542-546

77) Quintanilla Pérez, Víctor

"Determinación de procesos y áreas de riesgos en los Andes Centrales de Chile mediterráneo: casos de estudio"

Pirineos, 44 (143-144): 99-110

78) Rubio Moreno, P.

"Desplazamiento estacional de la línea de nieves en los Andes Centrales de Chile"

Notes de Geografía Física, 23: 85-90

79) Ciorino N., Rossana

"Chile: el género como gancho político de la modernidad posible"

América Latina, Hoy. Revista de Ciencias Sociales, (9): 71-74

1993

80) Gangas Geisse, Mónica

"Geografía de los años ochenta en Chile" en I Congreso Nacional de Geografía sobre Latinoamérica (La Rábida, 1992), 1993: 449-456

Título de la obra colectiva Latinoamérica. Territorios y países en el umbral del siglo XXI

81) Puncel Chornet, Alfonso

"Patrones y tendencias de la urbanización en Chile desde 1950 a 1982" en I Congreso Nacional de Geografía sobre Latinoamérica (La Rábida, 1992), 1993: 429-436

Título de la obra colectiva Latinoamérica. Territorios y países en el umbral del siglo XXI

82) Palacios Estremera, María Teresa; Ríos Clemente, María Asunción

"Los recursos naturales, una base de desarrollo e integración regional. El caso de Chile" en I Congreso Nacional de Geografía sobre Latinoamérica (La Rábida, 1992), 1993: 189-198 
Título de la obra colectiva Latinoamérica. Territorios y países en el umbral del siglo XXI

83) Caravaca Barroso, Inmaculada

"Concentración urbana y marginación social en Santiago de Chile" en I Congreso Nacional de Geografía sobre Latinoamérica (La Rábida, 1992), 1993: 135-142

Título de la obra colectiva Latinoamérica. Territorios y países en el umbral del siglo XXI

\section{4) Estrada, Baldomero}

"Migración española en Chile. Características actuales de la colectividad" en X Seminario de Columbres 1992, 1993: 101-123

Título de la obra colectiva Pasado, presente y futuro de la emigración española a Iberoamérica

1992

85) Ferrando, F.J.

"Clasificación hidrodinámica de Chile"

Cuadernos de Investigación Geográfica, 1992-1993, 18-19: 57-74

86) Quintanilla Pérez, Víctor

"Cartografía de áreas de desastres en cuencas andinas de Chile central. Determinación de sectores de riesgo"

Cuadernos de Investigación Geográfica, 1992-1993, 18-19: 47-56

87) Castro, Roberto; Pattillo, Carlos

"Cuantificación de áreas verdes de la región metropolitana de Santiago de Chile mediante técnicas de percepción remota y SIG" en V Coloquio de Geografía Cuantitativa (Zaragoza, 1992), 1992: 265-289

88) Moreno Guerrero, Manuel

"Gestión y ciudad humanizada: un desafío posible. El caso de la periferia urbana de Chile" en V Congres Iberoamerica d'Urbanisme (Valencia, 1992) (Ponencias área 4: Periferias), 1992, 4: $11 \mathrm{p}$.

89) Hernández Gurruchaga, Hilario; Olave Farias, Dídima; Reyes Coca, Marco Aurelio

Chillan, ciudad intermedia de Chile

Boletín de la Real Sociedad Geográfica, 128: 275-299 
1991

90) Espinoza, Guillermo A.; Fuentes, Eduardo R.

"Variabilidad de las precipitaciones y erosión episódica: evidencias a distintas escalas en Chile central"

Pirineos, 41 (137): 65-77

91) Trivelli Oyarzun, Pablo

"Autoritarismo político y liberalismo urbano. El caso de Santiago de Chile bajo el régimen militar"

Ciudad y Territorio, 1990-1991, (86-87): 17-26

92) Bertrand, María

"Evolución de la planificación intercomunal de Santiago de Chile"

Ciudad y Territorio, 1990-1991, (86-87): 125-131

1990

93) Quintanilla Pérez, Víctor

"El levantamiento cartográfico de la vegetación de Chile a pequeña escala" Topografía y Cartografía, 7 (36): 44-48

1988

94) Martinic, Mateo

"La emigración asturiana en Magallanes (Chile)"

Boletín del Instituto de Estudios Asturianos, 42 (126): 277-289

1987

95) Salcedo, Sergio

"Las plantaciones forestales en Chile"

Pensamiento Iberoamericano, (12): 155-166

1986

96) Abalos Konig, José Antonio; Lira Cossio, Luís

"Desarrollo regional, liberalismo económico y autoritarismo político: Chile 1973-1984"

Pensamiento Iberoamericano, (10): 185-208 


\section{5}

\section{7) Quintanilla Pérez, Víctor}

"La sucesión de los pisos vegetales en los Andes de Chile. Antecedentes fitogeográficos"

Pirineos, 35 (125): 31-51

98) Rosas Vera, José

"La participación de la manzana. Como se modernizó Santiago de Chile"

Revista UR. Revista de Urbanismo, (3): 29-38

\section{4}

99) Sánchez Muñoz, Alfredo

"Clasificación numérica en Geografía: un ejemplo aplicado a las regiones de Chile"

Paralelo 37. Revista de Estudios Geográficos, 1984-1985, (8-9): 517-540

100) Hajek, Ernst R.; Fuentes, Eduardo R.; Espinosa, Guillermo A.

"Bases para una Geografía climática de Chile central"

Paralelo 37. Revista de Estudios Geográficos, 1984-1985, (8-9): 325-336

\section{3}

101) "Notas para la Historia de la Geografía contemporánea en Chile (1950)"

Revista de Geografía, 1982-1983, 16-17: 5-21

\section{1}

102) Capel Molina, José Jaime

"Algunas situaciones de tiempo típicas en la región de Magallanes-Tierra del Fuego (Chile)"

Paralelo 37. Revista de Estudios Geográficos, (5): 5-16

103) Muñoz Pérez, J.

"La Perouse, en Chile (Dos informaciones inéditas de marzo de 1786)"

Estudios Geográficos, nº 66, pp. 169-176 
REVISTAS

- Ager. Revista de Estudios sobre Despoblación y Desarrollo Rural http://www.rolde-ceddar.net/rolde/jsp/ceddar/2/2.4.jsp

Fundada en 2001 por el Centro de Estudios sobre la Despoblación y Desarrollo de Áreas Rurales (CEDDAR).

Revista anual especializada en la investigación sobre los procesos de despoblación, sus causas, características y consecuencias, y las políticas más adecuadas frente a ellos, así como, en general, los problemas del desarrollo rural y territorial.

- Anales de Geografía de la Universidad Complutense

http://www.ucm.es/BUCM/revistasBUC/portal/modules.php?name=Revis$\operatorname{tas} 2 \& \mathrm{id}=\mathrm{AGUC}$

Fundada en 1981 está coeditada por los Departamentos de Geografía Humana y Geografía Física-Análisis Geográfico Regional de la Universidad Complutense de Madrid.

Revista semestral que recoge en sus páginas temas relacionados con el análisis e interpretación del espacio geográfico y del conocimiento de la realidad física, humana y regional de España, con especial atención al espacio urbano y el entorno regional de Madrid.

- Anuario de Estudios Americanos

http://estudiosamericanos.revistas.csic.es/index.php/estudiosamericanos

Fundada en 1994 por la Escuela de Estudios Hispano-Americanos de Sevilla del Consejo Superior de Investigaciones Científicas. Revista orientada a la investigación histórica, también publica trabajos de otras materias como la Crítica Literaria, la Ciencia Política o la Antropología.

- Arqueología Espacial. Revista del Seminario de Arqueología y Etnología Turolense

Fundada en 1994 por la Facultad de Humanidades y Ciencias Sociales de la Universidad de Zaragoza. Revista anual cuyo ámbito de actuación se centra en las Humanidades.

- Boletín de la Asociación de Geógrafos Españoles

http://age.ieg.csic.es/boletin.htm

Fundada en 1979 por la Asociación de Geógrafos Españoles (AGE). Revista semestral cuyo ámbito de actuación se centra en la Geografía y el Medio Ambiente. 


\section{- Boletín de la Real Sociedad Geográfica}

http://www.realsociedadgeografica.com/es/site/boletin.asp

Fundado en 1876 por la Real Sociedad Geográfica. Revista anual cuyo ámbito de actuación se centra en la Geografía y disciplinas afines, tales como Cartografía, Geología, Ecología, Edafología, Economía, Demografía, Tecnologías de la Información Geográfica, etc.

- Boletín de Letras del Real Instituto de Estudios Asturianos

http://tematico.asturias.es/cultura/ridea/IndiceBoletinesLetras.html\#B1

Fundada en 1947 bajo el título de Boletín del Instituto de Estudios Asturianos, cambió su nombre en 1992. Contiene estudios de Prehistoria, Arqueología, Historia, Literatura, Filología, Folklore, Etnología, Musicología, etc., referidos a Asturias y su cultura.

- Ciudad y Territorio. Estudios territoriales

http://www.mviv.es/es/index.php?option=com_content\&task=view\&id= 102\&Itemid $=156$

Es resultado de la fusión en 1993 de las dos revistas Ciudad y Territorio (CyT, fundada en 1969) del IEAL y Estudios Territoriales (ET, fundada en 1981) del MOPU. Actualmente está editada por el Ministerio de Obras Públicas, Transporte y Medio Ambiente, Sección de Estado Medio Ambiente y Vivienda.

Revista especializada en el campo de las Ciencias Sociales, concretamente en el Espacio Territorial, donde convergen las materias relacionadas con el espacio social, tales como la Ecología, la Geografía Humana, la Urbanística, la Ordenación Territorial y el Urbanismo, en suma, en lo que se ha denominado la Coranomía.

\section{- Cuadernos de Investigación Geográfica}

http://www.unirioja.es/servicios/sp/ej/cig/cig.shtml

Fundada en 1980 por la Universidad de la Rioja, es continuación de la revista Cuadernos de Investigación: Geografía e Historia. Revista anual que recoge trabajos relacionados con la Geografía (Física, Humana y Análisis Geográfico Regional) y el Medio Ambiente.

\section{- Cuadernos Geográficos}

http://www.ugr.es/ cuadgeo/

Fundada en 1971 por los Departamentos de Geografía de la Universidad de Granada. Revista anual cuyo ámbito de actuación se centra en las relaciones entre la sociedad y el territorio que contribuyan al desarrollo de la Ciencia Geográfica en cualquiera de sus áreas de conocimiento, especialmente en España y Andalucía, Latinoamérica y los países mediterráneos. 


\section{- Documents d'Anàlisi Geogràfica}

http://ddd.uab.es/record/14

Fundada en 1982 por la Universidad Autónoma de Barcelona, a partir de 1994 es coeditada por la Unidad de Geografía de la Universidad de Gerona. Revista semestral cuyo ámbito de actuación se centra en la Geografía y el Medio Ambiente.

- Ería: Revista Cuatrimestral de Geografía

http://www.uniovi.es/geografia/revistaEria.html

Fundada en 1980 con el título Ería: Revista Geográfica, por el Departamento de Geografía de la Universidad de Oviedo. Su ámbito de actuación se centra en la Geografía y el Medio Ambiente.

\section{- Estudios Geográficos}

http://estudiosgeograficos.revistas.csic.es/index.php/estudiosgeograficos

Fundado en 1940 por el Instituto Juan Sebastián Elcano del Consejo Superior de Investigaciones Científicas, actualmente es editado por el Instituto de Economía, Geografía y Demografía del C.S.I.C.

Revista trimestral que recoge trabajos tanto de carácter conceptual y metodológico, como de análisis del espacio y territorio geográficos, dando entrada también a artículos relacionados con otras ciencias afines como la cartografía, geología, ecología, ingeniería forestal, edafología, economía, demografía, sociología, etc. Recientemente, la revista ha estado atenta a las nuevas tecnologías de la información geográfica (Sistemas de Información Geográfica y Teledetección).

\section{- Geofocus}

http://geofocus.rediris.es/

Fundada en 2001 por el Grupo de Tecnologías de la Información Geográfica (antes Grupo de Métodos Cuantitativos, Sistemas de Información Geográfica y Teledetección) de la Asociación de Geógrafos Españoles (AGE).

Revista que trata cuestiones teóricas, metodológicas y técnicas sobre obtención, tratamiento, análisis, difusión y utilización de la información geográfica.

\section{- Geographicalia}

http://www.unizar.es/geografia/geographicalia/principal.htm

Fundada en 1977 por el Departamento de Geografía y Ordenación del Territorio de la Universidad de Zaragoza. Revista cuatrimestral cuyo ámbito de actuación se centra en la Geografía y el Medio Ambiente. 


\section{- Norba-Arte}

http://www.unex.es/unex/servicios/servicio_publicaciones/novedades/index_html

Revista anual que publica la Universidad de Extremadura desde 1984, cuyos contenidos abarcan la totalidad de la Historia del Arte, con especial referencia al arte español.

\section{- Papeles de Geografía}

http://www.um.es/dp-geografia/revista-papeles.php

Fundada en 1984 por el Departamento de Geografía de la Universidad de Murcia, es continuación de la revista Papeles del Departamento de Geografía. Revista semestral cuyo ámbito de actuación se centra en la Geografía y el Medio Ambiente.

\section{- Paralelo 37. Revista de Estudios Geográficos}

http://www.iealmerienses.es/

Fundada en 1977 por el Instituto de Estudios Almerienses de la Diputación Provincial de Almería. Revista anual cuyo ámbito de actuación se centra en la Geografía y el Medio Ambiente.

\section{- Pensamiento Iberoamericano}

http://www.pensamientoiberoamericano.org/

Fundada en 1982, en la actualidad es editada por la Agencia Española de Cooperación Internacional para el Desarrollo (AECID) y la Fundación Carolina.

Revista que apareció para tratar la actualidad de América Latina desde una perspectiva de economía política, temática que aún se mantiene pero incorporando otras perspectivas sociológicas y culturales de análisis de la realidad latinoamericana.

\section{- Pirineos}

http://www.ipe.csic.es/Revista_Pirineos.html

Fundada en 1945 por la Estación de Estudios Pirenaicos del Consejo Superior de Investigaciones Científicas, actualmente es editada por el Instituto Pirenaico de Ecología del C.S.I.C.

Revista anual que desde 1987 se dedica específicamente a la ecología de regiones montañosas. Publica trabajos relacionados con la dinámica de los ecosistemas de montaña, es decir, con los procesos y las relaciones que se establecen entre los seres vivos y entre estos últimos y el Medio Ambiente. 


\section{- Rábida}

http://www.diphuelva.es/

Fundada en 1985, es editada por la Diputación Provincial de Huelva. Revista de contenido americanista que aborda la realidad social y económica de Centroamérica y el Caribe.

- Revista de Estudios Regionales

http://www.revistaestudiosregionales.com/

Fundada en 1978 a iniciativa de la Facultad de Ciencias Económicas de la Universidad de Málaga. Sus primitivos Consejos Asesor y Directivo estaban constituidos por docentes de las Universidades de Málaga, Sevilla, Córdoba y Granada.

En la actualidad, el Consejo de Redacción de la revista está formado por las Universidades de Andalucía: Universidad de Almería, Cádiz, Córdoba, Granada, Huelva, Jaén, Málaga, Sevilla y la Universidad Internacional de Andalucía.

Revista de ciencias sociales cuyas áreas científicas con presencia predominante a lo largo de los años, aunque no únicas, han sido: Economía, Geografía, Ciencia Política, Historia, Sociología, Ciencias Jurídicas, Antropología.

- Revista de Teledetección

http://www.aet.org.es/?q=revista

Fundada en 1993 por la Asociación Española de Teledetección (AET), publica trabajos relacionados con las diversas aplicaciones de la Teledetección y con su desarrollo metodológico.

- Scripta Nova. Revista Electrónica de Geografía y Ciencias Sociales http://www.ub.edu/geocrit/nova.htm

Fundada en 1997 por la Facultad de Geografía e Historia de la Universidad de Barcelona. Revista cuyo ámbito de actuación se centra en la Geografía y el Medio Ambiente.

\section{- Serie Geográfica}

http://www.geogra.uah.es/inicio/publicaciones.php

http://dspace.uah.es/dspace/handle/10017/546

Fundada en 1991 por la Universidad de Alcalá de Henares. Revista anual cuyo ámbito de actuación se centra en la Geografía y el Medio Ambiente. 


\section{- Topografía y Cartografía}

http://www.coit-topografia.es/

Fundada en 1984 por el Ilustre Colegio Oficial de Ingenieros Técnicos en Topografía de Madrid. Su ámbito de actuación se centra en la Geografía y el Medio Ambiente.

Fernando Arroyo Ilera (Departamento de Geografía, Universidad Autónoma de Madrid)

$\mathbf{M}^{\mathrm{a}}$ Asunción Martín Lou (Instituto de Economía, Geografía y Demografía, CSIC)

Flor Rodríguez Sierra (Real Sociedad Geográfica) 